\title{
Rheumatology-Ophthalmology Collaborative Uveitis Units may Improve the Diagnostic and Therapeutic Approach of this Pathology: Experience from a Uveitis Unit in a Secondary Spanish Hospital
}

\author{
Ángel de la Mora ${ }^{1 *}$, Elena Aurrecoechea ${ }^{2}$, Ana Diez del Corral ${ }^{1}$ and Jaime Calvo ${ }^{2}$ \\ ${ }^{1}$ Ophthalmology Unit, Hospital Sierrallana of Torrelavega, Spain \\ ${ }^{2}$ Rheumatology Unit, Hospital Sierrallana of Torrelavega, Spain
}

*Corresponding author: Angel de la Mora, Ophthalmology Unit, Hospital Sierrallana of Torrelavega, Spain, Tel: +34676279736; E-mail: ampecs@yahoo.com Received date: June 28, 2016; Accepted date: August 11, 2016; Published date: August 20, 2016

Copyright: (c) 2016 de la Mora A, et al. This is an open-access article distributed under the terms of the Creative Commons Attribution License, which permits unrestricted use, distribution, and reproduction in any medium, provided the original author and source are credited.

\section{Abstract}

Purpose: The aim of this study is analyze the Etiology of the Uveitis diagnosed in the first three years of a Uveitis unit in a small hospital and share the experience and organization of a collaborative Rheumatology-Ophthalmology Uveitis Unit.
\end{abstract}

Methods: This study includes 136 patients with Uveitis.

Results: The most common form of Uveitis was anterior Uveitis (67.2\%) and the most common diagnoses were Ankylosing spondylitis (17.8\%), Herpes (14.3\%), HLA-B27+ (9.5\%), Fuchs Heterochromic Iridocyclitis (3.5\%).

Posterior Uveitis were $16.8 \%$ and the most common diagnoses were toxoplasmosis (42.9\%), Serpiginous choroidopathy (23.8\%), Tuberculosis (4.8\%) and Vogt Koyanagi Harada disease (4.8\%).

Panuveitis was diagnosed in $8.8 \%$ of the cases and the most frequent causes were Behçet's disease (18.8\%), Endophthalmitis (9\%), and Toxoplasmosis (9\%).

Intermediate Uveitis with $7.2 \%$ of the diagnoses, the most frequent were Sarcoidosis (11\%), syphilis (11\%), and multiple sclerosis $(11 \%)$.

Conclusion: This secondary center based study shows the difference in type of Uveitis and etiology in a secondary hospital from a tertiary one.

\section{Keywords: Uveitis; Medical units}

\section{Introduction}

Uveitis is an intraocular inflammation that can be associated with systemic diseases, such as infectious, inflammatory and autoimmune diseases.

Uveitis is one of the most common causes of blindness, it accounts for $5-20 \%$ of all cases of legal blindness and $10 \%$ of all severe visual disabilities are due to Uveitis in the developed world [1].

Many patients require systemic treatment, in addition to topical treatment, with a high potential for side effects, both ocular and systemic. All of these features justify a multidisciplinary approach for Uveitis, so in the recent times it has been advocated the creation of Uveitis Units composed of ophthalmologist and Rheumatologist or Internist, who working together can reach a better success rate in diagnosis and treatment in Uveitis patients [2]

The objectives of this study are sharing our experience and providing the results after 3 years working together in a Uveitis Unit.

\section{Method}

Sierrallana Hospital is a university hospital that serves an area of 165.000 inhabitants. The Uveitis Unit in our hospital is composed of 2 ophthalmologists and one rheumatologist that work together in an outpatient office one day per week attending Uveitis patients.

This study spans the first 3 years of activity of the Uveitis Unit and includes 136 patients new and existing. It doesn't include pediatric patients because our hospital doesn't provide care for children.

All patients were examined first by one ophthalmologist who performs a thorough ocular history and examination, including best corrected visual acuity, slit-lamp exam of anterior segment, vitreous and retina, intraocular pressure and other test as Optical Coherence Tomography (OCT) or Intravenous Fluorescein Angiography (IVFA) as needed [3-5].

Patients are asked to fill out a questionnaire based on the one on www.uveitis.org that the patient completes in the waiting room while the pupil is dilating. With all this data a first classification and a differential diagnosis is presented to the rheumatologist that takes a medical history and performs a general examination, then if the diagnosis is not certain other tests are ordered, in a stepwise manner, 
Citation: de la Mora A, Aurrecoechea E, del Corral AD, Calvo J (2016) Rheumatology-Ophthalmology Collaborative Uveitis Units may Improve the Diagnostic and Therapeutic Approach of this Pathology: Experience from a Uveitis Unit in a Secondary Spanish Hospital. J Arthritis 5: 215. doi:10.4172/2167-7921.1000215

Page 2 of 3

as needed by the differential diagnosis, as blood test, full blood count, biochemistry, Immunology and Serology ( mainly Toxoplasmosis and Syphilis); chest $\mathrm{x}$-ray if tuberculosis or sarcoidosis are suspected, or if an oral steroid course is needed $[4,5]$.

With the results of the history and examination a first diagnosis is made and topical or systemic treatment is started with antiinflammatory, anti-infective or immunosuppressive following the pattern of the disease and the grade of inflammation and the patient is controlled and evaluated in next visits by the ophthalmologist and rheumatologist until the end of the disease process.

Nomenclature for Reporting Clinical Data follows the recommendations by the SUN working group, that is classification in anterior Uveitis, intermediate Uveitis, posterior Uveitis and Panuveitis [6].

\section{Results}

With our experience in the first 3 years of the Uveitis Unit we have made up a study of the most frequent causes of Uveitis in the 136 patients seen in our hospital (Table 1). In our series the most common form of Uveitis was anterior Uveitis (67.2\%) and the most common diagnoses were Idiopathic (44\%), Ankylosing spondylitis (17.8\%), Herpes (14.3\%), HLA-B27 (9.5\%), Fuchs Heterochromic Iridocyclitis (3.5\%).

\begin{tabular}{|l|l|l|l|l|}
\hline & $\begin{array}{l}\text { Anterior } \\
\text { UV }\end{array}$ & $\begin{array}{l}\text { Intermediate } \\
\text { UV }\end{array}$ & $\begin{array}{l}\text { Posterior } \\
\text { UV }\end{array}$ & Pan UV \\
\hline$\%$ Total & 67.2 & 7.2 & 16.8 & 8.8 \\
\hline$\%$ primary UV & 4.7 & 0 & 28.8 & 0 \\
\hline $\begin{array}{l}\text { \% Systemic/rheumatic } \\
\text { UV }\end{array}$ & 36.9 & 22 & 0 & 18 \\
\hline$\%$ infectious UV & 14.3 & 11 & 47.7 & 18 \\
\hline$\%$ Idiopathic UV & 44 & 66 & 23.8 & 54.4 \\
\hline
\end{tabular}

Table 1: General characteristics.

The second most common Uveitis type was posterior Uveitis (16.8\%) and the most common diagnoses were toxoplasmosis (42.9\%), Serpiginous choroidopathy (23.8\%), idiopathic (23.8\%), Tuberculosis $(4.8 \%)$ and Vogt Koyanagi Harada disease (4.8\%).

Panuveitis was diagnosed in $8.8 \%$ of the cases and the most frequent causes were idiopathic (54\%), Behçet's disease (18.8\%), Endophthalmitis (9\%), and Toxoplasmosis (9\%).

The less frequent type of Uveitis was intermediate Uveitis with 7.2\% of the diagnoses, most of the cases were idiopathic (66.6\%), but Sarcoidosis (11\%), syphilis (11\%), and multiple sclerosis $(11 \%)$ were other etiologies found (Table 2).

There were no eyes with final visual acuity worse than 20/200 in these 3 years except for Endophthalmitis cases.

\section{Discussion}

Creation of Uveitis Units is a recent fact in hospitals that tries to improve the diagnostic approach and treatment of Uveitis, a disease that can disguise systemic problems that may risk patients' sight or even their lives. In these Units Ophthalmologists share their expertise in ocular examination allowing a pattern classification and an evaluation of the response to treatment, while Rheumatologists finetune diagnoses, adjust treatments, steroids, immunosuppressives, or biological agents as needed [7].

\begin{tabular}{|c|c|c|c|}
\hline $\begin{array}{l}\text { Anterior } \\
\text { Uveitis } 67.2 \%\end{array}$ & $\begin{array}{l}\text { Intermediate } \\
\text { Uveitis } 7.2 \%\end{array}$ & $\begin{array}{l}\text { Posterior Uveitis } \\
16.8 \%\end{array}$ & Panuveitis $8.8 \%$ \\
\hline Idiopathic $44.0 \%$ & Idiopathic $66.6 \%$ & $\begin{array}{l}\text { Toxoplasmosis } \\
42.9 \%\end{array}$ & Idiopathic 54.4\% \\
\hline $\begin{array}{l}\text { Ankylosing } \\
\text { spondylitis } \\
17.8 \%\end{array}$ & $\begin{array}{l}\text { Multiple } \\
\text { Sclerosis } 11.0 \%\end{array}$ & $\begin{array}{l}\text { Serpiginous } \\
\text { Choroidopathy } \\
23.8 \%\end{array}$ & $\begin{array}{l}\text { Behçet's } \\
\text { Disease } 18.8 \%\end{array}$ \\
\hline Herpes $14.3 \%$ & Syphilis $11.0 \%$ & Idiopathic $23.8 \%$ & $\begin{array}{l}\text { Endophthalmitis } \\
9.0 \%\end{array}$ \\
\hline $\begin{array}{l}\text { Fuchs } \\
\text { heterochromic } \\
\text { Iridocyclitis } 3.5 \%\end{array}$ & $\begin{array}{l}\text { Sarcoidosis } \\
11.0 \%\end{array}$ & $\begin{array}{l}\text { Tuberculosis } \\
4.8 \%\end{array}$ & Toxoplasmosis $9.0 \%$ \\
\hline Psoriasis $2.4 \%$ & & VKH $4.8 \%$ & \\
\hline $\begin{array}{l}\text { Sarcoidosis } \\
2.4 \%\end{array}$ & & & \\
\hline JIA $2.4 \%$ & & & \\
\hline TINU $1.2 \%$ & & & \\
\hline IBD 1.2\% & & & \\
\hline $\begin{array}{l}\text { Rheumatoid } \\
\text { Arthritis } 1.2 \%\end{array}$ & & & \\
\hline
\end{tabular}

Table 2: Etiology of Uveitis in a Secondary Hospital in Spain.

In our series the most frequently found Uveitis is Anterior Uveitis and most of them were idiopathic. The group associated with Spondyloarthropathies and HLA-B27 positive are the diagnoses more commonly found.

Intermediate Uveitis is mainly idiopathic and the most common posterior Uveitis is toxoplasmosis.

There aren't many series of Uveitis cases published so far in Europe, the biggest is the one by a German group with 1916 patients [8] and nearer are the ones by the Italian groups publish by Pivetti-Pezzi et al. [9], and Cimino et al. [10], and in Spain the series publish by Llorenç Bellés et al. [11] with 416 patients but as usually they belong to tertiary referral centers. In our study the cases belong to the first step of ophthalmological assistance.

Our data are in agreement with both of them regarding that the most frequent Uveitis was Anterior Uveitis and the less common was intermediate Uveitis.

When we compare our study with these studies we notice some differences:

- The main difference is that Anterior Uveitis reach to $67.2 \%$ in our study but only 45.4 in the German study $8,49.12 \%$ and $51.2 \%$ in the Italian studies $[9,10]$ and $36 \%$ in the Llorenç Bellés et al. study [11]. We believe that this great difference could reflect a referral bias because most mild Anterior Uveitis patients don't get to a 
Citation: de la Mora A, Aurrecoechea E, del Corral AD, Calvo J (2016) Rheumatology-Ophthalmology Collaborative Uveitis Units may Improve the Diagnostic and Therapeutic Approach of this Pathology: Experience from a Uveitis Unit in a Secondary Spanish Hospital. J Arthritis 5: 215. doi:10.4172/2167-7921.1000215

Page 3 of 3

tertiary hospital. And even more in our hospital Anterior Uveitis patients don't get any further tests if they respond to topical treatment and they don't recur, and so this can explain too that $44 \%$ of Anterior Uveitis patients don't get a diagnosis in our study as compared with $30.1 \%$ in the German group.

- The second difference is the much higher rate of toxoplasmosis in the Posterior Uveitis group in our study, $42.9 \%$ as compared with $24.7 \%$ in the German group 8 and $27 \%$ in the Llorenç Bellés et al. [11] study. The same referral bias could account for such difference as most toxoplasmosis uveitis has a clinical diagnosis and a good response to treatment in most cases. Another explanation of this difference could be the rural origin of most of our reference population.

The most important characteristic of our study is that this is an observational prospective study with no selection or referral bias as we are the first level of ophthalmological assessment. The main drawbacks are that the number of patients is not as big as in other studies and that children are excluded because our hospital doesn't provide assistance for pediatric rheumatology. The experience during these 3 years was good and rewarding both for professionals and patients.

\section{Conclusions}

Studies on the epidemiology of Uveitis are scarce and most of them are based on tertiary centers. We show in this study the different diagnoses found in the Uveitis patients examined in a secondary hospital and how a multidisciplinary approach increases the number of Uveitides diagnosed and then the prognosis of our patients by an earlier etiological treatment. At the same time a greater job satisfaction is achieved both for the Rheumatologist and the Ophthalmologist.

The number of patients is low and so this conclusions will have to be validated in other studies with more patients and if it is possible with a multicenter basis.

\section{Declaration of Interest}

The authors report no conflicts of interest. The authors alone are responsible for the content and writing of the paper.

\section{References}

1. Durrani OM, Tehrani NN, Marr JE, Moradi P, Stavrou P, et al. (2004) Degree, duration, and causes of visual loss in uveitis. Br J Ophthalmol 88: 1159-1162.

2. Bañares A, Jover JA, Fernandez B, del Castillo JMB, Garcia J, et al. (1997) Patterns of uveítis as a guide in making rheumathologic and immunologic diagnosis. Arthritis Rheum 40: 358-370.

3. Bloch-Michel E, Nussenblatt RB (1987) International Uveitis Study Group recommendations for the evaluation of intraocular inflammatory disease. Am J Ophthalmol 103: 234-235.

4. Diaz M (2011) Uveítis Protocolos Diagnósticos y Nuevas Estrategias Terapéuticas. Valencia: Ibañez \& Plaza Asociados, Valencia, Spain.

5. Harper SL, Chorich LJ, Foster CS (2002) Diagnosis of uveitis. In: Foster CS, Vitale AT. Diagnosis and Treatment of Uveitis. WB Saunders, Philadelphia, USA.

6. Jabs DA, Nussenblatt RB, Rosenbaum JT, Standardization of Uveitis Nomenclature (SUN) Working Group (2005) Standardization of uveitis nomenclature for reporting clinical data. Results of the First International Workshop. Am J Ophthalmol 140: 509-516.

7. Fonollosa A, Adán A (2011) Uveitis: a multidisciplinary approach. Arch Soc Esp Oftalmol 86: 393-394.

8. Jakob E, Reuland MS, Mackensen F, Harsch N, Fleckenstein M, et al. (2009) Uveitis subtypes in a german interdisciplinary uveitis center-analysis of 1916 patients. J Rheumatol 36: 127-136.

9. Pivetti-Pezzi P, Accorinti M, La Cava M, Gisoldi RAC, Abdulaziz MA (1996) Endogenous uveitis: an analysis of 1,417 cases. Ophthalmologica 210: 234-238.

10. Cimino L, Aldigeri R, Salvarani C, Zotti CA, Boiardi L, et al. (2010) The causes of uveitis in a referral centre of Northern Italy. Int Ophthalmol 30: 521-529.

11. Bellés VL, Civera AA, Garriga GE, Segura RC, Martínez JG, et al. (2012) Uveitis diagnosis characterization at a referral centre in the area of Barcelona, Spain. Med Clin (Barc) 138: 277-282. 